\title{
Polypropylene Meshes to Prevent Abdominal Herniation. Can Stable Coatings Prevent Adhesions in the Long Term?
}

\author{
Pieter J. Emans, ${ }^{1,2,3}$ Marc H.F. Schreinemacher, ${ }^{1}$ Marion J.J. Gijbels, ${ }^{4,5}$ Geerard L. Beets, ${ }^{1}$ \\ Jan-Willem M. Greve, ${ }^{1}$ Leo H. Koole, ${ }^{3}$ and Nicole D. Bouvy ${ }^{1}$ \\ ${ }^{1}$ Department of General Surgery, Maastricht University Medical Centre, Maastricht, The Netherlands; ${ }^{2}$ Department of \\ Orthopedic Surgery, Maastricht University Medical Centre, Maastricht, The Netherlands; ${ }^{3}$ Centre for Biomaterials Research, \\ Maastricht University Medical Centre, PO Box 616, 6200 MD Maastricht, The Netherlands; ${ }^{4}$ Department of Molecular \\ Genetics, Maastricht University Medical Centre, Maastricht, The Netherlands; and ${ }^{5}$ Department of Pathology, Maastricht \\ University Medical Centre, Maastricht, The Netherlands
}

(Received 11 January 2008; accepted 17 November 2008; published online 25 November 2008)

\begin{abstract}
Abdominal surgery is associated with a significant risk for incisional herniation. Hernia repair is routinely performed by implantation of synthetic meshes. Such meshes may cause serious adhesions between the implanted material and organs leading to intestinal obstruction or enterocutaneous fistulas. This study compares three knitted meshes for their capacity to prevent adhesion formation in an in vivo study. The meshes evaluated are polypropylene (Prolene ${ }^{\circledR}$ ), polypropylene coated with oxygenated regenerated cellulose - in principle - a biodegradable biomaterial (Proceed ${ }^{\circledR}$ ), and Prolene ${ }^{\circledR}$ coated with a nondegradable copolymer of the hydrophilic building block $N$-vinyl pyrrolidone (NVP) and the hydrophobic building block $n$-butylmethacrylate (BMA). The meshes were implanted in the abdomen of rats (followup 7 or 30 days). After 7 days, the formation of adhesions decreased in the order: Prolene ${ }^{\circledR}>$ NVP/BMA-coated Prolene ${ }^{\circledR}>$ Proceed $^{\circledR}$; after 30 days, this order changed into: Proceed ${ }^{\circledR}>$ Prolene ${ }^{\circledR}>$ NVP/BMA-coated Prolene ${ }^{\circledR}$. Both at 7 and at 30 days, Proceed ${ }^{\circledR}$ was the only mesh surrounded by macrophage cells that contained foreign materials, presumably degradation products of the (biodegradable) surface coating. The data indicate that long-term protection of implanted meshes against excessive adhesions may be achieved through stable biocompatible hydrogel surface coatings.
\end{abstract}

Keywords-Abdomen, Adhesion, Biocompatibility, Surgical mesh, Surface modification, Inflammation.

Address correspondence to Leo H. Koole, Centre for Biomaterials Research, Maastricht University Medical Centre, PO Box 616, 6200 MD Maastricht, The Netherlands. Electronic mail: 1.koole@ biochem.unimaas.nl,pj.emans@orthop.unimaas.nl

Leo H. Koole and Nicole D. Bouvy have contributed equally to this work.

\section{INTRODUCTION}

It is well known that abdominal surgery is associated with a significant risk for incisional hernia; the incidence has been estimated in the range of 10 $20 \%{ }^{16,22}$ The best method to repair these hernias is to implant a synthetic mesh that bridges the abdominal wall defect in a tension-free manner. ${ }^{6-8,20}$ Such meshes are implanted in an open procedure or, with increasing frequency, laparoscopically. Despite important clinical successes, it is obvious that the "ideal" mesh is still not available. For instance, meshes can become contracted and/or infected after implantation. ${ }^{9,24,25}$ Furthermore, adhesions between the visceral side of the mesh and adjacent organs can occur. ${ }^{12,24,26}$ These complications may have serious consequences, such as chronic pain, recurrence of the hernia or even intestinal obstruction and enterocutaneous fistulas. ${ }^{14,26}$

A review of the literature on the use of polymer meshes for incisional hernia repair learned that studies of biomaterial-tissue interactions have hardly played a role in the development of these implants. The majority of the commercial meshes are made out of knitted polypropylene (PP) fibers (e.g., Prolene ${ }^{\circledR}$, Marlex ${ }^{\circledR}$, Trelex $\left.^{\circledR}\right)$. PP is strong, chemically stable, and highly hydrophobic, but the material is by no means designed to engage in any favorable interaction with adjacent cells or tissues. ${ }^{24,27}$ Clinical experience, as well as animal experimentation, revealed extensive adhesions of tissues to the mesh as a frequent complication. However, there are clear indications that surface modifications of PP meshes can help to influence tissue reaction and thereby reduce adhesion formation., 5,26 Also, the frequent occurrence of adhesive interactions between the visceral side of the mesh and the bowel, leads one to suspect that the mesh surface may be too 
hydrophobic. This could explain why cells show an exceptionally strong affinity for these meshes.

The ideal mesh would have to show integration with the tissue of the abdominal wall (primarily to prevent mesh migration and hernia recurrence), but no adhesions whatsoever on the visceral side. Based on this idea, Van't Riet et al. recently performed an interesting in vivo model study, in which they implanted mesh structures that were coated with collagen on their visceral side. ${ }^{26}$ There was a clear positive effect of the collagen coating, with less visceral adhesions. Others have more or less successfully used different coatings from a biological origin such as sodium hyaluronate/ carboxymethylcellulose $^{10,26}$ or an absorbable layer of oxidized regenerated cellulose. ${ }^{14,15,26}$ Of course, it remains to be established whether or not these coatings are capable of adhesion prevention in the long term. In view of the fact that biological coatings are susceptible to hydrolytic or enzymatic degradation, it must be expected that these coatings will not provide long-term non-adhesiveness.

We hypothesized that a stable, synthetic, and biocompatible hydrophilic coating might be the biomaterial of choice in this respect. Herein, we report a study in which commercial PP mesh Prolene $^{\circledR}$, Ethicon, Johnson \& Johnson, Somerville, NJ, USA) was coated with an adherent hydrophilic copolymer, which was designed, synthesized, and fully characterized in our laboratory. The material was prepared from $N$-vinylpyrrolidinone (NVP) and $N$-butylmethacrylate (BMA) as the hydrophilic and hydrophobic building blocks, respectively. The choice for this biomaterial was based on our previous experience that these copolymers feature excellent biocompatibility, e.g., in contact with blood, ocular epithelium, and bone. ${ }^{2,13,18,23}$ The coated mesh was compared in a series of experiments in vivo (using a rat model) with the uncoated Prolene ${ }^{\circledR}$ and coated Proceed ${ }^{\circledR}$ mesh (Ethicon, Johnson \& Johnson, Somerville, NJ, USA). The latter is a three-layer composite of a PP mesh, an absorbable layer of oxidized regenerated cellulose, and an intermediate layer of polydioxanone. Adhesion formation was scored macroscopically and host response reactions were evaluated through histology.

\section{MATERIALS AND METHODS}

\section{Coating Preparation}

The hydrophilic copolymer was prepared from NVP and BMA (both monomers were purified by vacuum distillation), as described previously. ${ }^{11}$ Briefly, the monomers were mixed (molar ratio 1:1), radical initiator (AIBN, 1.5 molar\%) was added, and the mixture was transferred into a Teflon tube that was closed with a stopper on one end. The tube was immersed in an oil bath interfaced with a time/ temperature control system. After $24 \mathrm{~h}$, the materials were obtained as glassy rods. These were cut in pieces, and dissolved in ethanol $(10 \mathrm{~g}$ of copolymer in $500 \mathrm{~mL}$ ) under continuous mechanical stirring. The resulting viscous solution was mixed with the same volume of ethanol, and $500 \mathrm{mg}$ of triethyleneglycoldimethacrylate (TEGDMA) was added. After homogenization, the solution was applied as an all-around coating onto the PP mesh (Prolene ${ }^{\circledR}$ ). The coated mesh was dried in an oven $\left(65-70{ }^{\circ} \mathrm{C}\right)$ for $24 \mathrm{~h}$. This led to polymerization of the TEGDMA as a nonsoluble three-dimensional macromolecular network. This network prevents the dissolution of the hydrophilic biomaterial after implantation. All meshes were sterilized by treatment with ethylene oxide, degassed for at least 1 week and subsequently packed individually in sterile pouches.

\section{Water Contact Angle Measurement}

The water contact angle was measured by the sessille drop method. First, the NVP-BMA coating was applied to a glass surface as a thin homogeneous layer. A standard object glass for light microscopy was used for this purpose. Then, after thorough drying as described above, we placed approximately 10 water drops of $10 \mu \mathrm{L}$ onto the surface. The resulting drops were photographed from the side, using a digital camera with a macrolens. The water contact angles were measured from the images.

\section{Experiment and Animals}

Thirty-nine rats of the Wistar strain, weighing 250 $300 \mathrm{~g}$ were housed and cared for at the Central Animal Facilities of the University of Maastricht according to the appropriate standards. The experimental protocol was approved by the Committee of Animal Experiments of the University of Maastricht. The meshes were randomly implanted in the abdomen of rats; (i) implantation of a standard PP mesh (Prolene ${ }^{\circledR}$ ) $(n=15)$, (ii) a coated PP mesh $\left(\right.$ Proceed $\left.^{\circledR}\right)(n=12)$, or (iii) a NVP/BMA-coated Prolene ${ }^{\circledR}$ mesh $(n=11)$. Meshes were all sized $30 \times 20 \mathrm{~mm}^{2}$. With the Proceed $^{\circledR}$ and NVP/BMA-coated Prolene ${ }^{\circledR}$ mesh the coating was adjacent to the viscera. At 7 and 30 days postimplantation rats were sacrificed, adhesions were scored macroscopically, and the meshes were harvested to be processed for histology. This study was performed independently from all the manufacturers. 


\section{Surgical Procedure}

Throughout the procedure, nonpowdered sterile gloves were used. Rats were anaesthetized with ketamine hydrochloride $(100 \mathrm{mg} / \mathrm{kg})$ and xylazine $(5 \mathrm{mg} / \mathrm{kg})$. The abdomen was shaved and the skin disinfected with $2 \%$ iodine, and covered with sterile drapes. The abdomen was opened through a midline incision of $4 \mathrm{~cm}$. The mesh was introduced intraperitoneally and fixated with two sutures of polypropylene 4-0 (Prolene ${ }^{\circledR}$, Ethicon, Johnson \& Johnson, Somerville, NJ, USA). Thereafter, the peritoneum and fascia were closed with a running suture of polyglactin 4-0 (Vicryl ${ }^{\circledR}$, Ethicon, Johnson \& Johnson, Somerville, NJ, USA). The skin was closed intracutaneously with a running suture of polyglecaprone 4-0 (Monocryl ${ }^{\circledR}$, Ethicon, Johnson \& Johnson, Somerville, NJ, USA).

\section{Functional Macroscopic Evaluation}

Rats were sacrificed by an overdose of $\mathrm{CO}_{2}$ inhalation. Directly after sacrifice, the abdomen was opened widely along the circumference of the mesh. The incisions were made along three of the four sides of a rectangle; the fourth side served as a hinge for the mesh and adherent tissues. This procedure ensured that the meshes were not damaged, and that proper evaluation of any adherence between the mesh and adjacent tissues was possible. The amount of adhesion formation was then scored macroscopically. In the case of adhesions the organs involved were recorded and a photograph was taken. A qualitative scoring system according to the literature was used., ${ }^{1,26}$ For each implant, adhesion scores were determined by two independent researchers, on the basis of three subscores: (i) extent $(0$, no adhesions; $1,1-25 \%$; 2,26 $50 \% ; 3,51-75 \% ; 4,76-100 \%$ of the mesh surface involved); (ii) type ( 0 , no adhesions; 1 , filmy; 2 , dense; 3 , capillaries present), and (iii) tenacity ( 0 , no adhesions; 1 , easily fall apart; 2 , require traction; 3 , require sharp dissection). When different scores were attributed to a sample, the score of a third independent researcher, blinded to the study group and the scores of the first two researchers, gave a majority for one of the two first scores. The percentage of meshes which had an adhesion with organs including liver, spleen, bowel, and stomach was also examined. Hereafter all implanted meshes along with surrounding tissues were retrieved for histological examination.

\section{Microscopy}

Scanning electron microscopy was performed with a Philips XL 30 instrument, $12 \mathrm{keV}$. Fluorescence and bright field microscopy was performed with a Nikon
Eclipse E800 instrument (fluorescence setting; Texas Red filter (excitation, $540-580 \mathrm{~nm}$; dichroic mirror 595).

\section{Histology}

After macroscopic evaluation the mesh was locally excised with the surrounding tissue $(\sim 1 \mathrm{~cm})$. Each excised specimen was split in four equal pieces and fixated in vials with a $4 \%$ formaldehyde solution. After dehydration in increasing concentrations of alcohol, two pieces of each specimen were embedded in glycol methacrylate (Technovit 7100; Heraeus Kulzer, Wehrheim, Germany). These were then sectioned at $5 \mu \mathrm{m}$ and stained with hematoxylin \& eosin (H\&E). The samples were evaluated by an experienced animal pathologist not familiar with the specific background of the different meshes. Tissue adjacent to the visceral side (i.e., PP with Prolene ${ }^{\circledR}$, oxidized regenerated cellulose with Proceed ${ }^{\circledR}$, and NVP/BMA with the NVP/BMA-coated Prolene ${ }^{\circledR}$ mesh) was scored for inflammation at 7 days, granulation tissue at 30 days, and intestinal organ (e.g., bowel, liver, etc.) adhesion formation ( - meaning absent, + slightly present, ++ moderately present,+++ abundantly present). Presence of (i) giant cells, (ii) granulocytes, (iii) fibroblasts, and (iv) macrophages were also scored accordingly. ${ }^{12,21}$

\section{Statistics}

Based on pilot work, the sample size was determined based on the power analysis of Sachs, with a power of $80 \%$, two-tailed and a confidence interval of $95 \%$. This resulted in a minimum of six meshes per group for the qualitative adhesion scoring system as described in literature. ${ }^{1,12,26}$ Statistics were performed by Mann-Whitney $U$ test. $P$-values $<0.05$ were considered significant.

\section{RESULTS}

\section{Mesh Coating}

Figure 1 shows the Prolene ${ }^{\circledR}$, Proceed ${ }^{\circledR}$, and NMP/ BMA-coated Prolene ${ }^{\circledR}$ mesh structures. Note that the knitted patterns for Prolene ${ }^{\circledR}$ and Proceed $^{\circledR}$ are markedly different, also with respect to pore density and pore size. Application of the NVP/BMA copolymer as a thin adherent coating onto the Prolene ${ }^{\circledR}$ mesh structure proceeded without difficulties. It was found to be essential that the concentration of the copolymer in the alcohol solution was kept below 1.5 mass $\%$. At higher concentrations (i.e., at higher viscosities), it was 

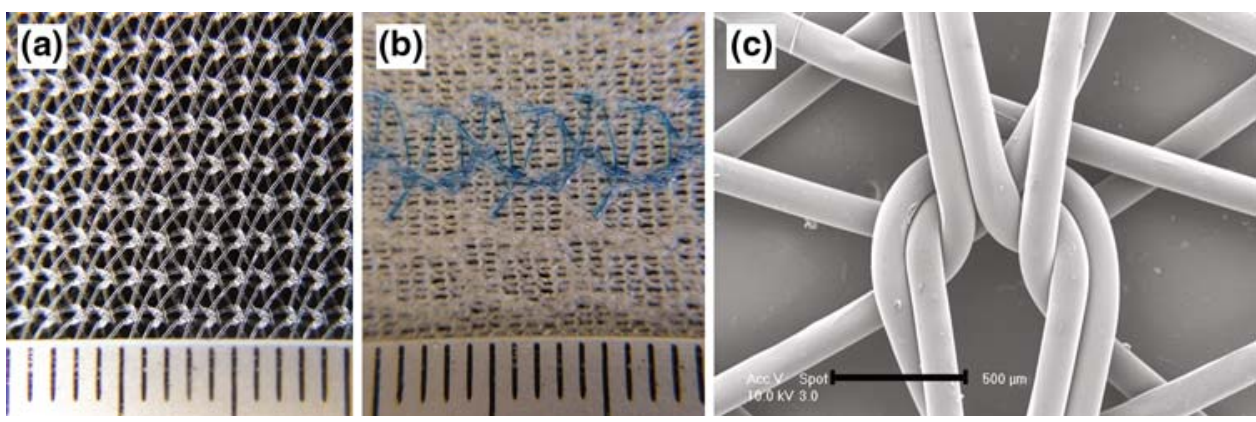

FIGURE 1. Photographs of different meshes. (a) Prolene ${ }^{\circledR}$ mesh (b) Proceed ${ }^{\circledR}$ mesh. Note the difference in knitted patterns (the ruler in (a) and (b) shows mm-scale; the spacings are $1 \mathrm{~mm}$ each). (c) Scanning electron micrograph of a NVP/BMA-coated Prolene $^{\otimes}$ mesh. Note that the coating results in a smooth and regular surface (scale bar corresponds with $500 \mu \mathrm{m}$ ).

unavoidable that pores were partially or completely filled with copolymer. Scanning electron microscopy, especially suitable for evaluating the surface morphology, revealed a smooth and very regular surface (Fig. 1c). In order to evaluate distribution of the coating, a piece of PP mesh was only partly coated with NVP/BMA solution to which a trace of the fluorescent dye Rhodamine 6 was added. With fluorescence microscopy, the coating was clearly identified on the treated and not on the untreated side (Fig. 2). A uniform distribution of the coating can therefore be ascertained. As for hydrophilic features, the application of the NVP/BMA coating resulted in a moderately hydrophilic surface, as was shown in our previous work. ${ }^{11}$ Specifically, the NVP/BMA coating used in this work (molar ratio NVP:BMA $=9: 1$ ) gives a water contact angle in the range of $32-36^{\circ}$. In comparison with PP (water contact angle of $85-87^{\circ 11}$ ), the surface hydrophilicity has increased substantially as a result of the surface treatment. Furthermore, flexibility of the mesh was not influenced by NVP/BMA coating although this was not verified in any quantitative manner. Both the increased hydrophilicity and the surface smoothness resulting from the coating are responsible for the observed differences in biomaterial-tissue interactions (vide infra).

\section{General Observations}

All animals recovered quickly of anesthesia and were thriving and well during the entire experiment. One rat (Proceed ${ }^{\circledR}$ group) died just after implantation, most likely due to anesthetic overdose.

\section{Functional Macroscopic Evaluation}

A typical example of an explanted NVP/BMAcoated Prolene ${ }^{\circledR}$ mesh (30 days follow-up) is depicted in Figs. $3 \mathrm{a}$ and $3 \mathrm{~b}$. In this particular case, extent
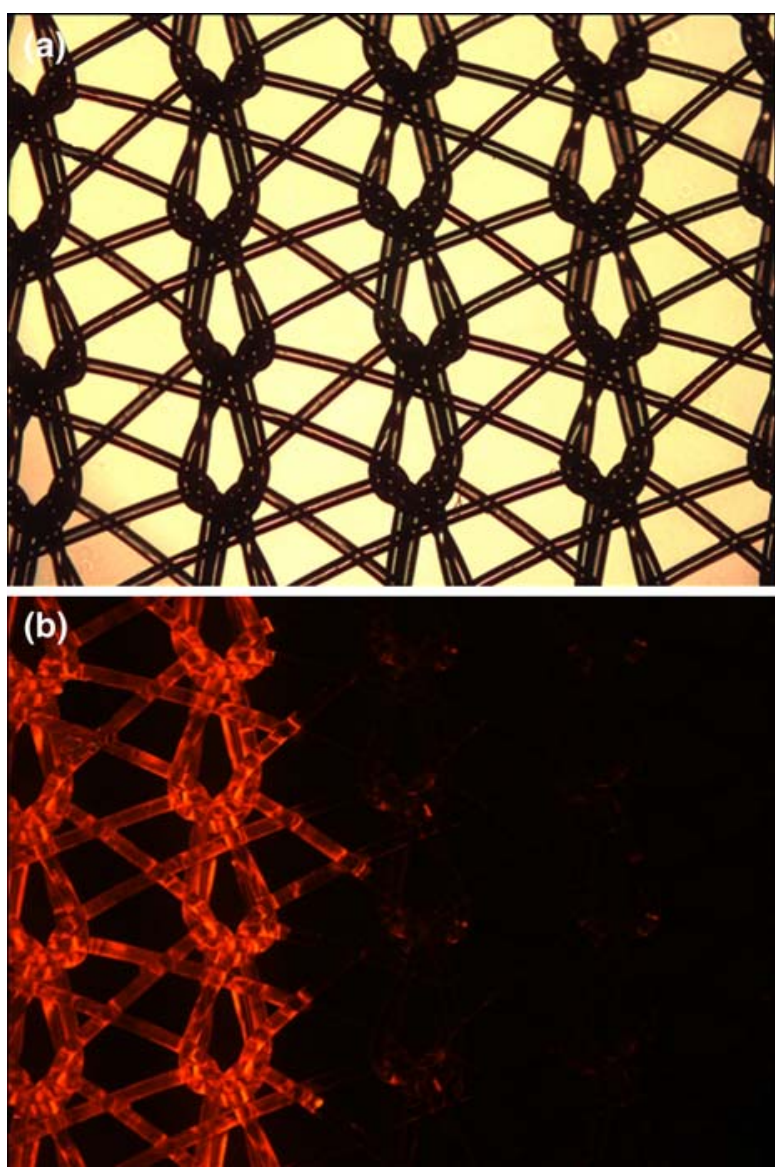

FIGURE 2. (a) Microscopic photograph (bright field) of the PP mesh partly treated with NVP/BMA solution containing fluorescent dye Rhodamine. The coating was applied on the left side of the mesh. (b) Fluorescence microscopy of the same sample as (a), illuminated with ultraviolet light that excites the dye. The image reveals that Rhodamine is spread evenly over the treated part of the mesh.

(0, no adhesions; $1,1-25 \% ; 2,26-50 \% ; 3,51-75 \%$; 4, $76-100 \%$ of the mesh surface involved), tenacity ( 0 , no adhesions; 1, easily fall apart; 2, require traction; 3 , require sharp dissection), and type ( 0 , no adhesions; 

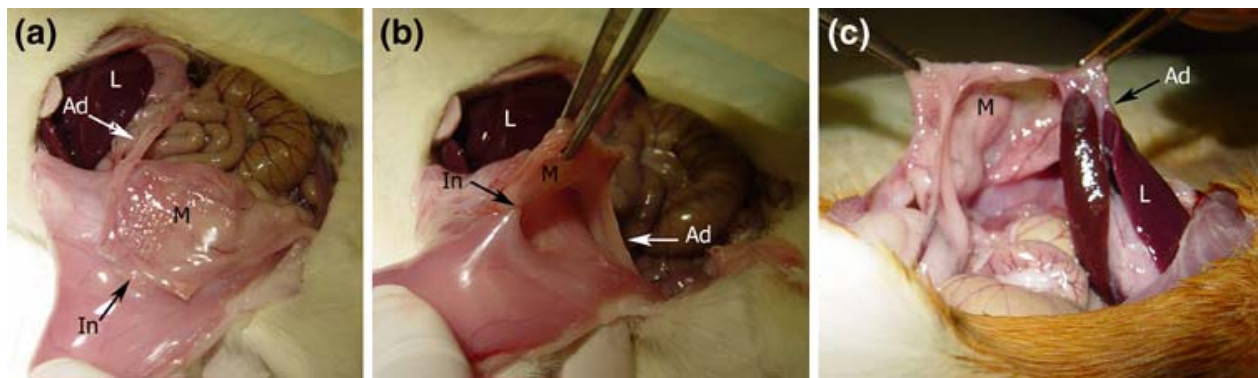

FIGURE 3. Representative macroscopic views of the meshes after implantation in the rat abdomen. (a) NVP/BMA-coated Prolene ${ }^{\circledR}$ mesh 30 days postimplantation, the abdomen is opened in a $U$ shape enabling a good macroscopic evaluation. The mesh is indicated by the letter $M$ and the liver by the letter L. Note the site of incorporation (In) and the typical adhesions (Ad) at the uncoated edges of the mesh. (b) The same rat as in (a), the mesh is lifted, again note the site of incorporation (In) and adhesion (Ad) formation to the uncoated edges of the mesh. (c) A Prolene ${ }^{\circledR}$ mesh (M) 7 days postimplantation, showing adhesion formation to the liver (L), similar observations were found for Proceed ${ }^{\circledR}$ and Prolene ${ }^{\circledR} 30$ days postimplantation.

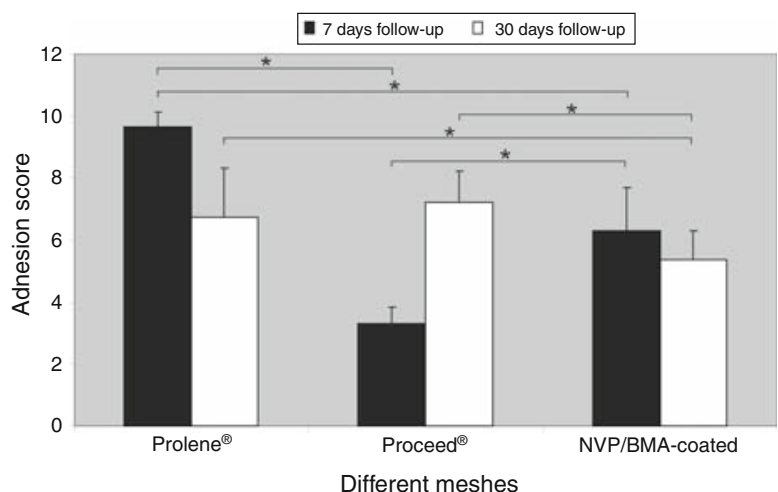

FIGURE 4. Macroscopic adhesion scores at 7 and 30 days postimplantation. After 7 days follow-up, the Proceed ${ }^{\circledR}$ had a significant $(p<0.05)$ better score $(3.3)$ compared to Prolene ${ }^{\circledR}$ and NVP/BMA-coated Prolene ${ }^{\circledR}$ (9.6 and 6.3, respectively). Interestingly while the adhesion scores of Prolene ${ }^{\circledR}$ and NVP/ BMA-coated Prolene ${ }^{\circledR}$ meshes improved, the adhesion score of the Proceed ${ }^{\circledR}$ meshes worsened. At this time the adhesion score of the NVP/BMA-coated Prolene ${ }^{\circledR}$ mesh (5.4) was significantly $(p<0.05)$ better compared to Proceed $^{\circledR}(7.2)$ and Prolene $^{\circledR}(6.7)\left({ }^{*}\right.$ indicates $p$-values $\left.<0.05\right)$.

1, filmy; 2, dense; 3, capillaries present) of adhesions were scored as 2, 2, and 3, respectively. Figure 4 presents total adhesion scores with different meshes at 7 and 30 days follow-up. At 7 days follow-up, the adhesion scores decreased in the following order: Prolene ${ }^{\circledR} \quad(9.3 \pm 0.5)>\mathrm{NVP} /$ BMA-coated Prolene $^{\circledR}$ $(7.3 \pm 0.5)>$ Proceed $^{\circledR}(3.3 \pm 0.5)$; all differences are statistically significant $(p<0.05)$. Adhesions with omentum or scrotal fat were observed with virtually all meshes. Adhesions with abdominal organs like liver, spleen, stomach, and bowel were observed in $87 \%$ of the Prolene ${ }^{\circledR}$ meshes, $83 \%$ of the NVP/BMA-coated Prolene ${ }^{\circledR}$ meshes, and $50 \%$ of the Proceed ${ }^{\circledR}$ meshes. At 30 days follow-up, the order changed into: Proceed ${ }^{\circledR}$ $(7.2 \pm 1.1)>$ Prolene $^{\circledR}(7.0 \pm 1.2)>\mathrm{NVP} / \mathrm{BMA}$-coated Prolene $^{\circledR}(5.4 \pm 0.5)$. At 30 days, the total adhesion score of NVP/BMA-coated Prolene ${ }^{\circledR}$ meshes was significantly lower than Prolene ${ }^{\circledR}$ and Proceed ${ }^{\circledR}$. This finding was in concordance with the adhesions found with abdominal organs (liver, spleen, stomach, and bowel); $0 \%$ with NVP/BMA-coated Prolene ${ }^{\circledR}, 29 \%$ with Prolene ${ }^{\circledR}$, and $50 \%$ with Proceed ${ }^{\circledR}$.

\section{Histological Evaluation}

At 7 days follow-up, all implants initiated a comparable inflammatory response. This was accompanied by neovascularization, influx of mainly granulocytes, and fibroblast proliferation. Macrophages were abundantly present with Proceed $^{\circledR}$ and only slightly or not present with NVP/BMA-coated Prolene ${ }^{\circledR}$ and Prolene ${ }^{\circledR}$ meshes, respectively. The macrophages near the Proceed ${ }^{\circledR}$ mesh were also found to contain foreign material. This probably indicates that phagocytosis of the Proceed $^{\circledR}$ coating (oxidized regenerated cellulose and polydioxanone) is occurring. The macrophages observed in the NVP/BMA-coated Prolene ${ }^{\circledR}$ group were large and swollen but not filled with foreign material (Fig. 5). The number of granulocytes and giant cells were comparable for all groups (Table 1).

At 30 days follow-up, the NVP/BMA-coated Prolene ${ }^{\circledR}$ meshes showed a mild reaction, consisting of some granulation tissue with mostly fibroblasts, giant cells, and macrophages. A fibrous capsule encapsulated the NVP/BMA-coated Prolene ${ }^{\circledR}$ mesh forming all around the NVP/BMA-coated Prolene ${ }^{\circledR}$ mesh (Fig. 5) and no adhesions were observed (Table 1). The Prolene ${ }^{\circledR}$ meshes showed adhesions together with more granulation tissue, mostly more fibroblasts.

The Proceed $^{\circledR}$ meshes still provoked a reaction attended with many fibroblasts, giant cells, and macrophages. Again, macrophages filled with a foreign material from the mesh were observed, together with a clearly degraded coating (Fig. 5c). 


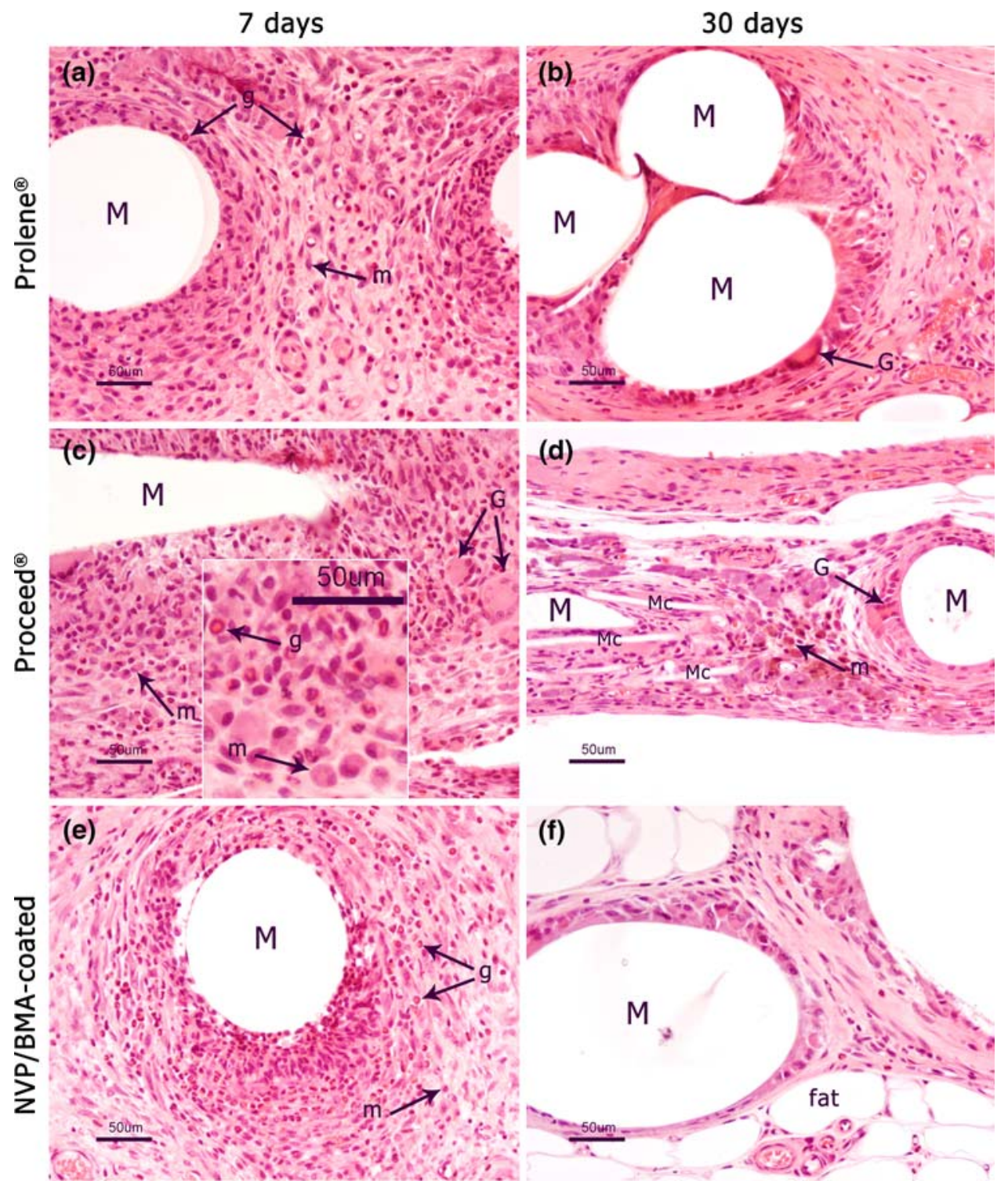

FIGURE 5. Representative H\&E stained sections. (a) Prolene ${ }^{\circledR}$ mesh after 7 days follow-up. (b) Prolene ${ }^{\circledR}$ mesh after 30 days follow-up. (c) Proceed ${ }^{\circledR}$ mesh after 7 days follow-up. Inset shows macrophages containing foreign material. (d) Proceed ${ }^{\circledR}$ mesh after 30 days follow-up. (e) NVP/BMA-coated Prolene ${ }^{\circledR}$ mesh after 7 days follow-up. (f) NVP/BMA-coated Prolene ${ }^{\circledR}$ mesh after 30 days follow-up. M, mesh; Mc, mesh coating present in giant cells; m, macrophage; g, granulocyte; G, giant cell.

TABLE 1. Histological assessment.

\begin{tabular}{|c|c|c|c|c|c|c|c|}
\hline 7 days follow-up & $n$ & Inflammation & Granulocytes & Fibroblasts & Giant cells & Macrophages & Adhesions \\
\hline Prolene $^{\circledR}$ & 8 & ++ & ++ & ++ & $-/+$ & $-1+$ & ++ \\
\hline Proceed $^{\circledR}$ & 6 & ++ & + & +++ & ++ & +++ & $-/+$ \\
\hline NVP/BMA coated & 7 & ++ & ++ & +++ & $-1+$ & + & ++ \\
\hline 30 days follow-up & $n$ & Granulation & Granulocytes & Fibroblasts & Giant cells & Macrophages & Adhesions \\
\hline Prolene $^{\circledR}$ & 7 & ++ & $-1+$ & ++ & + & $-1+$ & + \\
\hline Proceed $^{\circledR}$ & 5 & - & - & +++ & ++ & +++ & $-1+$ \\
\hline NVP/BMA coated & 5 & $-/+$ & $-/+$ & + & + & + & - \\
\hline
\end{tabular}

- means absent; + slightly present; ++ moderately present; +++ abundantly present. 


\section{DISCUSSION AND CONCLUDING REMARKS}

This study shows that modification of the mesh surface can modulate the inflammatory response provoked by implantation of a mesh. Our clearest observation of this effect was made through histology on the 30-day follow-up samples of meshes and surrounding tissues. The uncoated Prolene ${ }^{\circledR}$ meshes were found to invoke a moderate inflammatory response in their immediate vicinity, characterized by the presence of active macrophages. A stronger inflammatory response was observed with the Proceed ${ }^{\circledR}$ meshes, presumably due to ongoing phagocytosis of the oxidized regenerated cellulose and polydioxanone coating. Remnants of foreign material were observed in macrophages and giant cells. The NVP/BMA-coated Prolene ${ }^{\circledR}$ mesh initially provoked a profound acute inflammation. After 30 days, only a mild inflammatory reaction was left. At this stage, these meshes were found to be surrounded by a fibrous capsule. Although not exclusively proven, encapsulation of the mesh may prevent adhesion formation in the long term.

Macroscopically, different grades of adhesions were observed at 7 and 30 days follow-up. Most remarkable were the adhesions with Proceed ${ }^{\circledR}$. Although adhesion scores were the lowest at day 7 , they increased by day 30 and exceeded adhesion scores of NVP/BMA-coated Prolene ${ }^{\circledR}$ mesh and Prolene ${ }^{\circledR}$. The adhesion scores of the NVP/BMA-coated Prolene ${ }^{\circledR}$ and Prolene ${ }^{\circledR}$ mesh, however, declined toward day 30 . A possible explanation might be the prolonged activation of the macrophages with Proceed ${ }^{\circledR}$. Activation of macrophages induces the release of inflammatory cytokines and attracts cells like fibroblasts. Prolonged presence of active fibroblasts then might induce more tenacious adhesions, as observed. ${ }^{14,26}$ Overall, the results of the microscopic analyses (histology) and the macroscopic adhesion scores were consistent.

Interestingly, Baptista et al. have reported that inflammation leads to adhesions, generally within 7 days. ${ }^{3}$ We observed, in most cases, fewer adhesions after 30 days, as compared to 7 days follow-up, which is in agreement with findings of Burger et al. ${ }^{5}$ who also showed that adhesion formation may decrease at 30 days follow-up. The only exception was the Proceed mesh, with an increase in the adhesion effect between 7 and 30 days follow-up. It is generally accepted that evaluation of meshes at 7 and 30 days represents different phases of wound healing. At 7 days, the inflammatory phase has just ended, and the proliferative phase has just started. At 30 days, the remodeling phase has started and prosthetic material covered with a lining of autologous cells (neoperitoneum) is expected not to form any new adhesions. ${ }^{5}$ Adhesions that have formed before, however, will remain a persistent inflammatory process, even in adhesions aging over 20 years. ${ }^{4}$ It is tempting to argue that the remodeling phase may lead to a decreased adhesion formation. Since adhesion formation changes even until 30 days follow-up, it is hard to predict when the remodeling phase will end, what should be defined as long-term follow-up, and what will be the final adhesion formation.

Our data reveal that the stable hydrophilic polymer mesh coating has a beneficial effect on adhesion formation after implantation of a mesh, albeit that our experiments were carried out in a validated rat model deviating from the actual application: repair of incisional hernias. Incisional hernias are a major surgical complication occurring in at least $10-20 \%$ of all abdominal operations and need to be repaired in about one third of these patients. ${ }^{6,17}$ Large trials have shown that hernia repair should be performed by mesh placement and no longer by primary resuturing of the hernia because of unacceptably high recurrence rates. ${ }^{7,19}$ Mesh repair, however, is not free from complications, with significant factors being technical failure such as insufficient fixation of the mesh to the abdominal wall and complications which are a result of the mesh biomaterial itself. The latter is especially true if the biomaterial provokes inflammation, or if its surface is prone to bacterial infection. Biomaterials which are currently used in this particular application (i.e., PP and poly(tetrafluoro)ethylene) may be optimized using a stable coating and this may ultimately translate into decreased failure rates for incisional hernia repair, to the benefit of a large group of patients.

Finally, four remarks may be appropriate:

1. The predictive value of this study may be more specific for clinical cases in which the mesh is implanted in direct contact with the viscera and not separated from the viscera by an intact peritoneum.

2. In this study the aim was to examine the biocompatibility and adhesion formation of three different mesh surfaces. Fixation of the mesh to the abdominal wall is clinically relevant to prevent hernias to reoccur. In our study, the two Prolene ${ }^{\circledR}$ sutures used for fixation always resulted in a good local incorporation. This aspect will be examined in future studies.

3. Since it is not clear if adhesion formation changes after 30 days, a follow-up beyond 30 days is needed to precisely evaluate the performance of the NVP/ BMA-coated Prolene ${ }^{\circledR}$ meshes over the course of time.

4. A hydrophilic coating (degradable or stable) may be exploited in another manner as well, i.e., as a reservoir for controlled release of an antibiotic agent. A hydrophilic surface per se may play a role in the 
prevention of bacterial adhesion, ${ }^{9}$ while controlled swelling of the coating after implantation provides a means to engineer and control the release kinetics, at least in principle.

Points 1, 3, and 4 are subjects of further investigations in our laboratories.

\section{OPEN ACCESS}

This article is distributed under the terms of the Creative Commons Attribution Noncommercial License which permits any noncommercial use, distribution, and reproduction in any medium, provided the original author(s) and source are credited.

\section{REFERENCES}

${ }^{1}$ Adhesion Scoring Group. Improvement of interobserver reproducibility of adhesion scoring systems. Fertil. Steril. 62:984-988, 1994.

${ }^{2}$ Aldenhoff, Y. B., M. L. Knetsch, J. H. Hanssen, T. Lindhout, S. J. Wielders, and L. H. Koole. Coils and tubes releasing heparin. Studies on a new vascular graft prototype. Biomaterials 25:3125-3133, 2004. doi:10.1016/ j.biomaterials.2003.10.012.

${ }^{3}$ Baptista, M. L., M. E. Bonsack, I. Felemovicius, and J. P. Delaney. Abdominal adhesions to prosthetic mesh evaluated by laparoscopy and electron microscopy. J. Am. Coll. Surg. 190:271-280, 2000. doi:10.1016/S1072-7515(99) 00277-X.

${ }^{4}$ Binnebosel, M., R. Rosch, K. Junge, P. Lynen-Jansen, V. Schumpelick, and U. Klinge. Macrophage and T-lymphocyte infiltrates in human peritoneal adhesions indicate a chronic inflammatory disease. World J. Surg. 32:296-304, 2008. doi:10.1007/s00268-007-9330-x.

${ }^{5}$ Burger, J. W., J. A. Halm, A. R. Wijsmuller, S. ten Raa, and J. Jeekel. Evaluation of new prosthetic meshes for ventral hernia repair. Surg. Endosc. 20:1320-1325, 2006. doi:10.1007/s00464-005-0706-4.

${ }^{6}$ Burger, J. W., R. W. Luijendijk, W. C. Hop, J. A. Halm, E. G. Verdaasdonk, and J. Jeekel. Long-term follow-up of a randomized controlled trial of suture versus mesh repair of incisional hernia. Ann. Surg. 240:578-583, 2004; discussion 583-575.

${ }^{7}$ Cassar, K., and A. Munro. Surgical treatment of incisional hernia. Br. J. Surg. 89:534-545, 2002. doi:10.1046/j.13652168.2002.02083.x.

${ }^{8}$ Eisner, L., and F. Harder. [Incisional hernias]. Chirurg. 68:304-309, 1997. doi:10.1007/s001040050193.

${ }^{9}$ Engelsman, A. F., H. C. van der Mei, R. J. Ploeg, and H. J. Busscher. The phenomenon of infection with abdominal wall reconstruction. Biomaterials 28:2314-2327, 2007. doi:10.1016/j.biomaterials.2007.01.028.

${ }^{10}$ Greenawalt, K. E., T. J. Butler, E. A. Rowe, A. C. Finneral, D. S. Garlick, and J. W. Burns. Evaluation of sepramesh biosurgical composite in a rabbit hernia repair model. J. Surg. Res. 94:92-98, 2000. doi:10.1006/jsre.2000.6020.

${ }^{11}$ Hanssen, H. H., G. M. Wetzels, A. Benzina, F. H. van der Veen, T. Lindhout, and L. H. Koole. Metallic wires with an adherent lubricious and blood-compatible polymeric coating and their use in the manufacture of novel slipperywhen-wet guidewires: possible applications related to controlled local drug delivery. J. Biomed. Mater. Res. 48:820-828, 1999. doi:10.1002/(SICI)1097-4636(1999)48:6 $<820:: A I D-J B M 9>3.0 . \mathrm{CO} ; 2-\mathrm{K}$.

${ }^{12}$ Hooker, G. D., B. M. Taylor, and D. K. Driman. Prevention of adhesion formation with use of sodium hyaluronate-based bioresorbable membrane in a rat model of ventral hernia repair with polypropylene mesh - a randomized, controlled study. Surgery 125:211216, 1999.

${ }^{13}$ Jansen, E. J., R. E. Sladek, H. Bahar, A. Yaffe, M. J. Gijbels, R. Kuijer, S. K. Bulstra, N. A. Guldemond, I. Binderman, and L. H. Koole. Hydrophobicity as a design criterion for polymer scaffolds in bone tissue engineering. Biomaterials 26:4423-4431, 2005. doi:10.1016/ j.biomaterials.2004.11.011.

${ }^{14}$ Judge, T. W., D. M. Parker, and R. C. Dinsmore. Abdominal wall hernia repair: a comparison of sepramesh and parietex composite mesh in a rabbit hernia model. J. Am. Coll. Surg. 204:276-281, 2007. doi:10.1016/j. jamcollsurg.2006.11.003.

${ }^{15}$ Kayaoglu, H. A., N. Ozkan, S. M. Hazinedaroglu, O. F. Ersoy, A. B. Erkek, and R. D. Koseoglu. Comparison of adhesive properties of five different prosthetic materials used in hernioplasty. J. Invest. Surg. 18:89-95, 2005. doi:10.1080/08941930590926357.

${ }^{16}$ Kingsnorth, A. The management of incisional hernia. Ann. R. Coll. Surg. Engl. 88:252-260, 2006. doi:10.1308/ 003588406 X106324.

${ }^{17}$ Kingsnorth, A., and K. LeBlanc. Hernias: inguinal and incisional. Lancet 362:1561-1571, 2003. doi:10.1016/S01406736(03)14746-0.

${ }^{18}$ Knetsch, M. L., Y. B. Aldenhoff, and L. H. Koole. The effect of high-density-lipoprotein on thrombus formation on and endothelial cell attachment to biomaterial surfaces. Biomaterials 27:2813-2819, 2006. doi:10.1016/ j.biomaterials.2005.12.025.

${ }^{19}$ Korenkov, M., S. Sauerland, M. Arndt, L. Bograd, E. A. Neugebauer, and H. Troidl. Randomized clinical trial of suture repair, polypropylene mesh or autodermal hernioplasty for incisional hernia. Br. J. Surg. 89:50-56, 2002. doi:10.1046/j.0007-1323.2001.01974.x.

${ }^{20}$ Luijendijk, R. W., W. C. Hop, M. P. van den Tol, D. C. de Lange, M. M. Braaksma, J. N. M. Ijzermans, R. U. Boelhouwer, B. C. de Vries, M. K. Salu, J. C. Wereldsma, C. M. Bruijninckx, and J. Jeekel. A comparison of suture repair with mesh repair for incisional hernia. N. Engl. J. Med. 343:392-398, 2000. doi:10.1056/NEJM2000081034 30603.

${ }^{21}$ Matthews, B. D., G. Mostafa, A. M. Carbonell, C. S. Joels, K. W. Kercher, C. Austin, H. J. Norton, and B. T. Heniford. Evaluation of adhesion formation and host tissue response to intra-abdominal polytetrafluoroethylene mesh and composite prosthetic mesh. J. Surg. Res. 123: 227-234, 2005. doi:10.1016/j.jss.2004.08.012.

${ }^{22}$ Mudge, M., and L. E. Hughes. Incisional hernia: a 10 year prospective study of incidence and attitudes. Br. J. Surg. 72:70-71, 1985. doi:10.1002/bjs. 1800720127.

${ }^{23}$ Pijls, R. T., T. Sonderkamp, G. W. Daube, R. Krebber, H. H. Hanssen, R. M. Nuijts, and L. H. Koole. Studies on a new device for drug delivery to the eye. Eur. J. Pharm. Biopharm. 59:283-288, 2005. doi:10.1016/j.ejpb.2004.08. 011. 
${ }^{24}$ Scheidbach, H., C. Tamme, A. Tannapfel, H. Lippert, and $\mathrm{F}$. Kockerling. In vivo studies comparing the biocompatibility of various polypropylene meshes and their handling properties during endoscopic total extraperitoneal (TEP) patchplasty: an experimental study in pigs. Surg. Endosc. 18:211-220, 2004. doi:10.1007/s00464-0038113-1.

${ }^{25}$ Scheidbach, H., A. Tannapfel, U. Schmidt, H. Lippert, and F. Kockerling. Influence of titanium coating on the biocompatibility of a heavyweight polypropylene mesh. An animal experimental model. Eur. Surg. Res. 36:313317, 2004. doi: $10.1159 / 000079917$.
${ }^{26}$ Van't Riet, M., P. J. de Vos van Steenwijk, F. Bonthuis, R. L. Marquet, E. W. Steyerberg, J. Jeekel, and H. J. Bonjer. Prevention of adhesion to prosthetic mesh: comparison of different barriers using an incisional hernia model. Ann. Surg. 237:123-128, 2003. doi:10.1097/000006 58-200301000-00017.

${ }^{27}$ Zheng, F., Y. Lin, E. Verbeken, F. Claerhout, M. Fastrez, D. De Ridder, and J. Deprest. Host response after reconstruction of abdominal wall defects with porcine dermal collagen in a rat model. Am. J. Obstet. Gynecol. 191:19611970, 2004. doi:10.1016/j.ajog.2004.01.091. 